\title{
Production Logging and its Implementation: A Technical Review
}

\author{
Mohammad Sumon Chowdhury ${ }^{1 *}$, Hossain Al Tanjil ${ }^{2}$, Sigma Akter $^{3}$, Mohammad Al Amin ${ }^{1}$, \\ Simanto Kumar Pal ${ }^{1}$ \\ ${ }^{I}$ Bangladesh University of Engineering and Technology (BUET), Bangladesh \\ ${ }^{2}$ Freiberg University of Mining and Technology, Germany \\ ${ }^{3}$ MARA University of Technology, Malaysia
}

\begin{abstract}
*Corresponding Author: Mohammad Sumon Chowdhury, Bangladesh University of Engineering and Technology (BUET), Bangladesh
\end{abstract}

\begin{abstract}
Traditional well log determines the geological and geophysical data of the wellbore and formation fluids properties like porosity, permeability, saturation, resistivity and shale volume. All these are measured during exploration and development stages of a drilling hole. During production or injection of a well, several problems like lost circulation, production tubing integrity and such others need to be known which are very important. Production logging determines wellbore fluid flowing data during production of oil, gas or water. Production problems determination and the remedy of the problems are designed based on production logging. Several production logging tools are used to determine the flow behavior of the formation fluids as well as identification of the top of cement. For multi-layers reservoir, perforation is essential for producing oil or gas from several layers. Production log determines the location of perforation. Spinner flow meter is used to determine the formation fluids velocity whereas Gradiomanometer is for fluids density. Besides, individual sensors are used in production logging for appraisement of various properties. This paper provides a technical review on production logging and its tools along with the modification for horizontal well. The result of this study will help to understand the importance and technique of production log very effectively.
\end{abstract}

Keywords: Production log, Production logging tools, Sensors, Spinners, Probe hold-up

\section{INTRODUCTION}

Well $\log$ is a popular term to the geologists, geophysicist and to the petroleum engineers. It is a measurement technique of some wellbore data. It can be defined as the continuous recording of geophysical and petro physical parameter along a borehole by specified procedure. It is called wellbore logging or geophysical logging. The measurement parameters are always plotted against depth so that it can be interpreted by geologist or geophysicist to obtain wellbore and formation parameters [1]. Logging plays an important role in oil and gas industry. The wellbore parameters as well as formation rock and fluid parameters are determined by logging procedures. All data are recorded either at surface which is real time mode or recorded in the memory at the hole which is memory mode to an electronic data format. Porosity, permeability, saturation, radioactivity, shale volume, wellbore diameter and some other rock and fluid properties can be determined by geophysical logging.

Logging is the cheapest method of collecting data related to geophysical properties of a well. Rather than drilling wells with related coring tools, it is much more cost-effective to obtain wire line logs using high-tech logging equipment. In the process of coring, the core needs to bring at the surface for their complete analysis. This can be problematic because the pressure in the well can damage softer sediments in this core. In this regard, logging data offers better insights about the natural characteristics of sediments or rocks without causing any damage to them [2]. On the other hand, coring procedure is both time consuming and cost effective. Coring has risk of sample damages. Considering all the factors, wellbore logging is most effective for getting geological and petro physical data from the formation.

\subsection{Types of Geophysical Logging}

There are several logs that measure specific parameters. According to Rider (2002), geophysical logs are classified as ten classes which are used for individual parameters measurement. Logs types and measurement parameters are shown in the table 1.1. 
Table1.1. Common wire line log and geophysical well measurements [1]

\begin{tabular}{|c|c|}
\hline Log Type & Formation parameter measured \\
\hline Caliper & Hole diameter \\
\hline Temperature & Borehole temperature \\
\hline SP (Self-Potential) & Spontaneous electrical current \\
\hline Gamma ray & Resistance to electrical current \\
\hline Resistivity & Conductivity of electrical current \\
\hline Induction & Velocity of sound propagation \\
\hline Sonic & Reaction to gamma ray bombardment \\
\hline Density & Reaction to gamma ray bombardment \\
\hline Photoelectric & Reaction to neutron bombardment \\
\hline Neutron &
\end{tabular}

A logging unit consists of a winch unit, wire line cable and logging tools. Winch unit is a mechanical set up which is used for pull up and pull down of wire line cable. It is in truck on the land and on the ship in the offshore. A set up for logging operation is shown in fig-1.1.

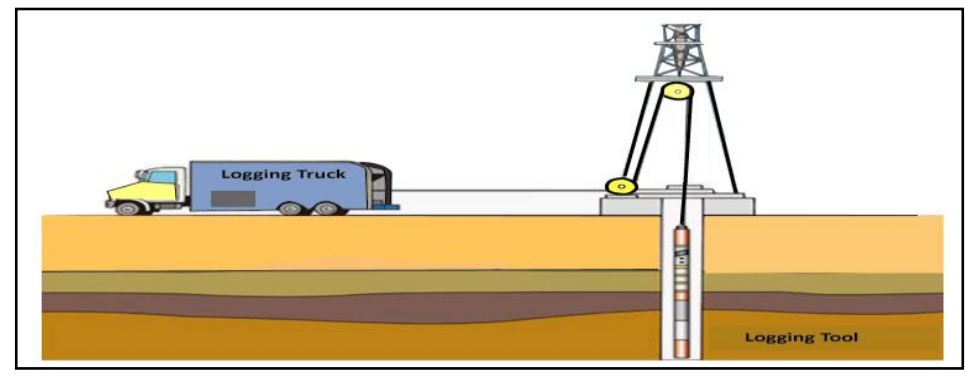

Figure1.1. Basic set up for wire line logging, modified after [3]

\subsection{Production Logging}

Production log is dissimilar to other logs. Several geophysical logs are run in the well to measure some properties before production started and during exploration and development stages. Production logging is a cased hole logging technique. This is the logging procedure to gather wellbore fluids data during production or injection. When wellbore is completed, production logging tools are run. Production logging tools are used for the measurement which involves wide range of sensors and measurements tools. This technique has also interpretation tools which evaluate the formation properties, analyze the formation fluid movements inside and outside of the wellbore and estimate the production flow rate for each layer of the formation [4].

Most of the $\log$ s like sonic $\log$, resistivity $\log$, density $\log$, neutron $\log$ and rest of the $\log$ are used to determine the wellbore parameter as well as formation fluid characteristics up to the wellbore completion. This is the basic difference than production logs. Production logs are run only when the completion is done and production is started. During enhance recovery, production log is run to observe the fluids movement near and in the wellbore. The production logging tools are small in diameter and are run through tubing for evaluation of the well as it is producing.

\section{LITERATURE REVIEW}

\subsection{Logging and Production Logging}

Production logs were first used in 1930's for measuring the temperature of wells but over the decades other measurements such as pressure, fluid density and hold up were developed consequently [5]. Wellbore parameters like wellbore diameter, hole integrity, caving, formation porosity, permeability, resistivity and some others characteristics are measured by traditional wire line logging. This measurement also may be gained by logging while drilling tool. Production logging is applicable when the production is started. The general purpose of production logging is to evaluate the behavior and type of fluids within the wellbore during either production or injection operations. Although there are a number of logging services available to the industry which provide this type of information. A standard group of production logging tools like spinner flow meter device, fluid identification tools, borehole pressure and temperature measurements along with natural gamma ray and casing collar locators are used for the operation. Production logs are simply combination of a wide range of sensors, measurement tools which are used with proper methods of analyzing and help the reservoir 
management team such as drilling engineers, production engineers and reservoir engineers to obtain their required data of measurement [6]. Production logging measurements usually consist of several types of logs. They are temperature, fluid density, fluid capacitance, pressure, and spinner-flow meter, along with standard casing collar locators and gamma ray logs. These measurements are usually made in a single logging run for reducing rig time, and make all measurements under the same wellbore conditions.

\subsection{Production Log Application}

There are many applications of production logging in both open hole and cased hole environments.

- Lost circulation zones and underground blowouts are identified in open hole condition.

- Cased hole flow performance are also measured by production log.

- Locates top of cement

- Evaluates gravel pack quality, location of perforations

- Determine permeability comparisons, locations of leaks

- Hold-up behaviors like water/oil/gas hold up for several depths are determined by production logs data.

- Besides leakage identification between production tube and production casing is also determined by production logs.

- Production casing integrity is checked by production logs.

- The effect of enhanced recovery is also observed by production logging procedure.

\subsection{Production Log Running Situations}

Production logging depends on some criteria. Production log can be run in some special scenario and several condition of the reservoir which are mentioned below $[7,8]$.

- New well: Production logging can be applied in new wells in order to evaluate the initial production of the well

- Unstable well: Production $\log$ is used in the well which production is suddenly decreased or suddenly increased.

- Problem determination: Production log should be run periodically in the production well to make sure that any problems such as gas or water coning or fingering remain or not before serious reduction in production occurs.

- Injection wells: Production $\log$ is run in the injection well to determine the injecting fluid entry point to the formation.

Beside production log can be applied in the multi-layers producing wells, before and after the acidizing procedures of a well and unreasonable water and gas production wells [9].

\subsection{Production Logging Tools}

Various types of production logging tools are used in production and injection wells. These tools are used in vertical, deviated, and horizontal wells. Flow velocity, gas hold up, fluid velocity and other auxiliary parameters are measured by Production Logging tools. The production logging tools are shown in fig. 2.1 [10]. Production log run depends on some several charges. This cost is kept as minimum as possible for the logging operation cost. These are equipment set up charge, surface pressure charge, cable run charge for maximum depth and logging charge per foot [11].

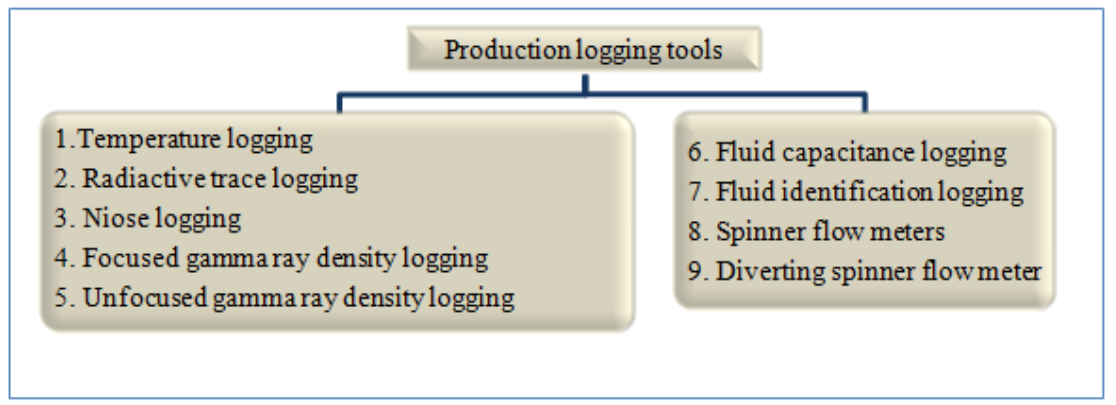

Figure2.1. Production logging tools 


\section{TECHNICAL DISCUSSION}

\subsection{Production Logging Tools Components}

The first administration of production logging tools such as temperature, flow meters, and density logging tools applied in the petroleum industries since the 1950s [4]. Today, modern production logging tools become available. So, interpretation becomes easier. Some of the main applications of production logging tools are well mechanical problems identification, completion processes efficiency analysis, production and injection scenarios observation and monitoring, reservoir characteristics and detection of cemented channels $[12,13]$. Production logging tools are also used to analyze and investigate the borehole performances. Beside this tool monitors the borehole inefficiencies by interpreting production logs $[14,15]$. Fig. 3.1 shows a production logging tools and fig. 3.2 shows the production logging tools components.

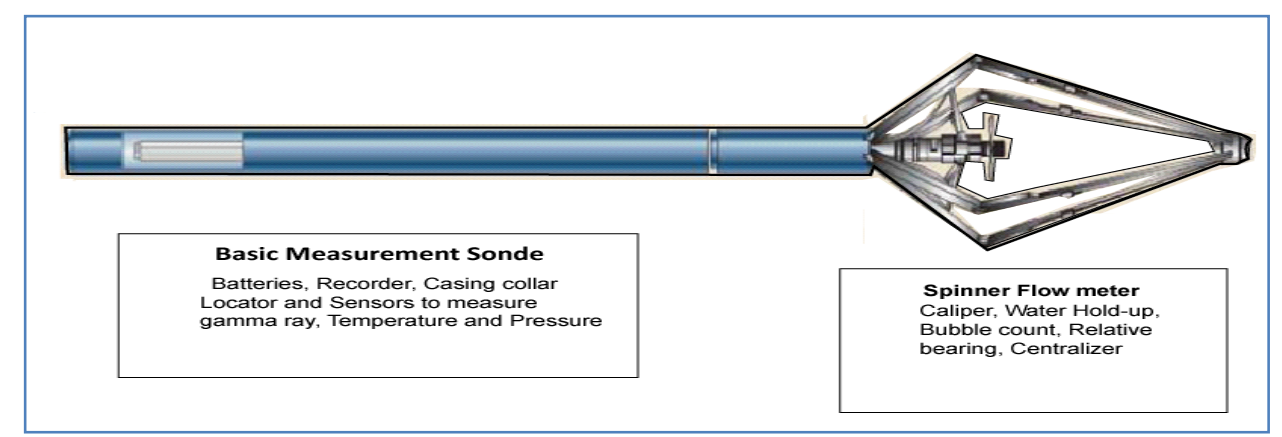

Figure3.1. Production logging tool string [6].

This tool string consist a full bore spinner and a sonde which measures the basic parameters. The spinner consist probe which measures the water hold up behavior. Caliper tool also remains in the spinner which measures wellbore diameter. In the sonde, there are some several sensors like pressure sensors, temperature sensors and gamma ray sensors.

Spinner flow-meter measures the formation fluid viscosity. The manometer sensors determine the mechanical displacement which further helps to calculate the formation pressure. From wellbore pressure data, well stability at the time of production logging can be determined. Beside, from pressure data fluid density and key parameters of the reservoir can be calculated by rate transient analysis.

Resistance temperature detector is the most common type of sensor which is used to measures the formation temperature during production or injection operation. This temperature helps to evaluate injection well performance as well as fracture treatment evaluation.

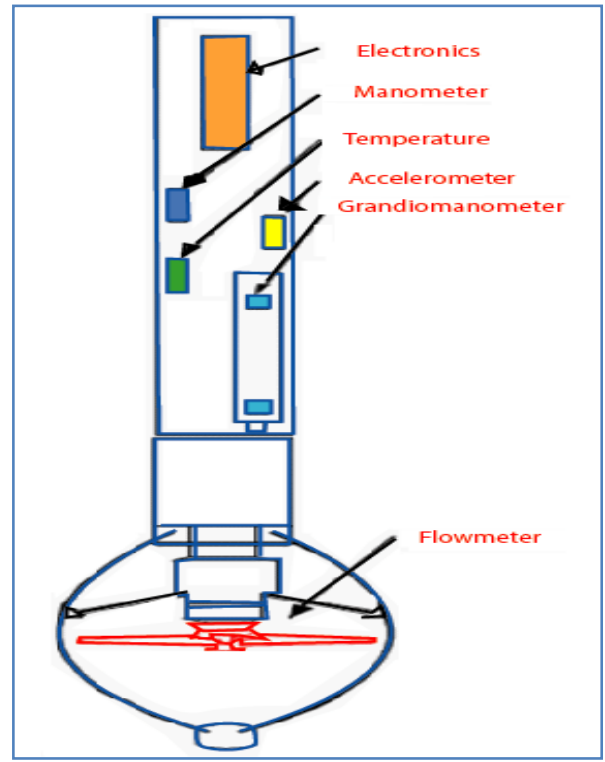

Figure3.2. Production Logging tools components, modified after [16, 17] 


\subsection{Fluid Velocity Measurement}

Spinner velocity tool is used for formation fluid velocity determination. A spinner flow meter consist a rotating blade. This blade turns when the fluid passes it. The rotational speed of the blade is measured in RPS (Revolution per Second). This rotational speed depends on mainly three factors. They are-

- Fluid velocity

- Fluid viscosity

- Friction factor of the spinner bearings

More the velocity of the fluid, more the rotational speed is. Less the friction of the bearings, more the rotational speed of the blade is. If the fluid viscosity is low, its velocity is high.

Velocity correction is needed as friction factor and fluid viscosity has effect on velocity. Before calculating the absolute fluid velocity, spinner velocity is corrected for relative tools speed [18]. Absolute fluid velocity is not equal to average speed of passing fluid in the pipe as there is friction. The spinner speed is converted to average speed by computer modeling after getting correction factor. There are three types of spinner flow meter. They are-

- full bore spinner flow meter

- continuous spinner and flow meter

- mini spinner flow meter

Full bore Spinner doesn't cover the whole pipe cross section. It is run at the bottom of the production logging tools string. It doesn't sweep more than $40 \%$ of cross section of casing and also don't have a progressive pitch. A full bore spinner is shown in fig. 3.3 [21].

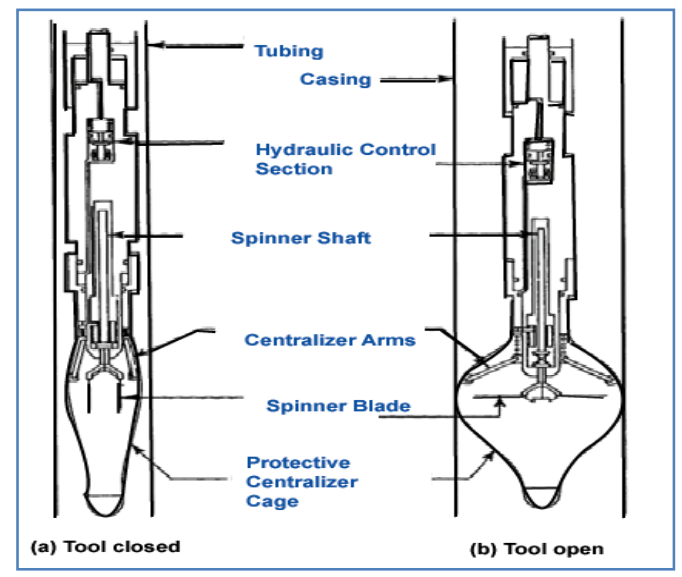

Figure3.3. Full bore spinners

Continuous spinner is also known as tubing spinner. It has a progressive pitch which is more effective in extracting Energy from well fluids. A continuous spinner is shown in fig. 3.4 and a mini spinner is shown in fig. 3.5 [18].

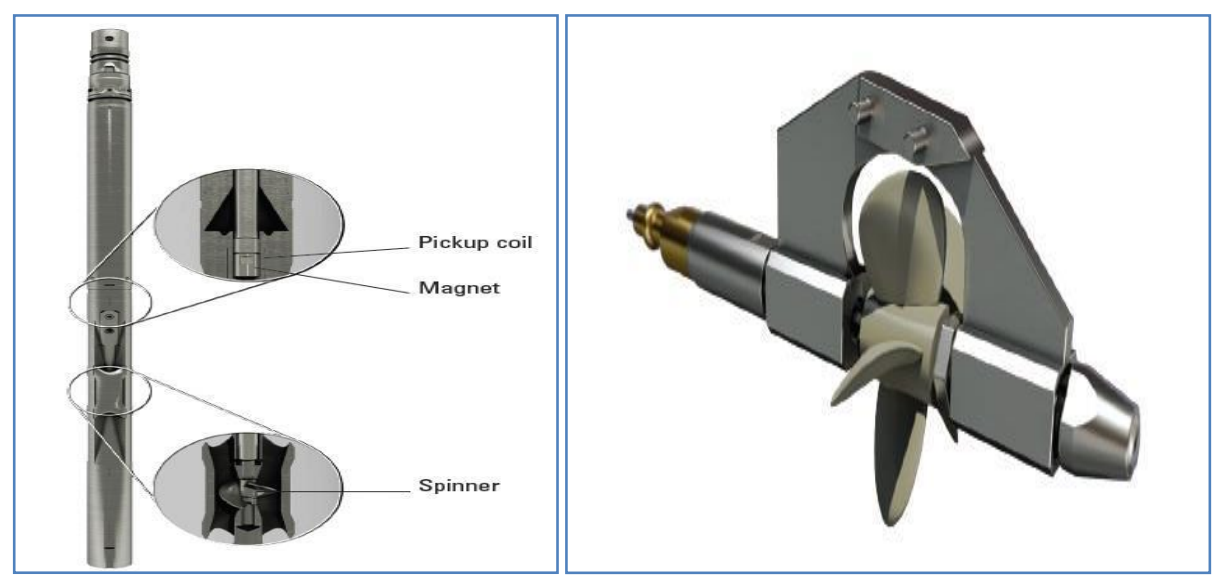

Figure3.4. Continuous spinners

Figure3.5. Mini spinners 
Mini spinner is used in horizontal well. This spinner is used so that the velocity of the fluid on vertical axis of pipe can be determined.

\subsection{Fluid Density Measurement}

Density is defined as the mass per unit volume. Production logging tools consist density measurement tool which is called Gradiomanometer. This tool is a non-radioactive which uses high resolution differential transducer. It is used for formation fluid density measurement. It has the sensor which reacts with the density differences. Generally gas is low denser than oil and water. This tool currently is used by Schlumberger Company.

\subsection{Probe Hold-Up Measurement}

Two common types of probe are used for hold up measurement. They are

1. GHOST probe

2. Water hold up probe

\section{GHOST Probe:}

It measures the hold -up by sensing the difference in optical reflectance and the reflected light from fluid. This tool can be used to determine the water hold up when gas is not present. The light created by LED passes through Y Coupler and reaches the optical probe. With total interior reflection, light beam is focused on the tip of the probe. If the reflective index of well fluid is high enough, light escapes from the probe. The light trapped is returned to photodiode by $\mathrm{Y}$ coupler and is converted to Voltage [5].

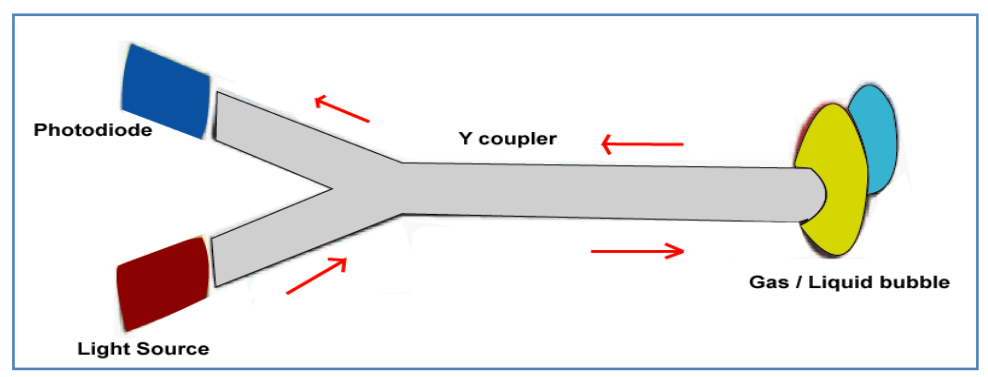

Figure3.6. Optical path of GHOST light beam, modified after [5]

\section{Water Hold Up Probe:}

It is used to distinguish water and hydrocarbons by using electrical conductivity of water.

In water continuous phase, current is sent from the tip of the Probe and returns to the body of the tool. If there is any oil droplet sits on the tip of the probe, circuit will be broken and the probe distinguishes the oil.

In oil Continuous phase, there is no current between tip of the probe and body of the tool. If a water droplet sits on the tip of the probe, it cannot create a circuit but if this droplet sits between electrical probe and ground wire, there will be a current [5].

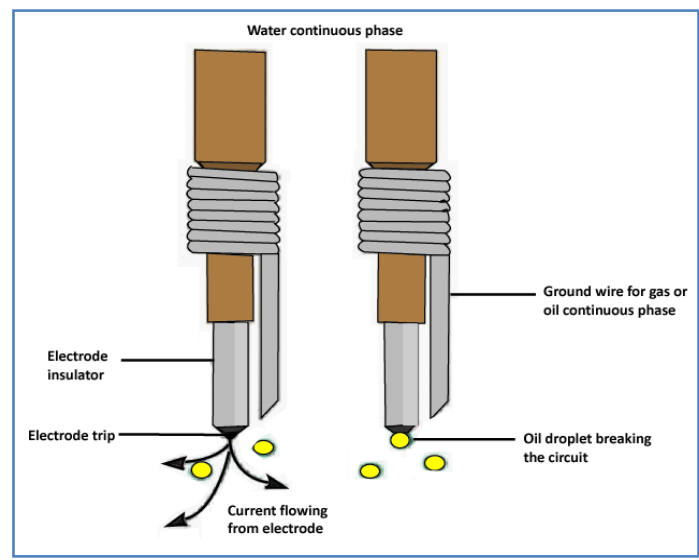

Figure3.7. Water holdup probe, water-continuous phase, modified after [5] 


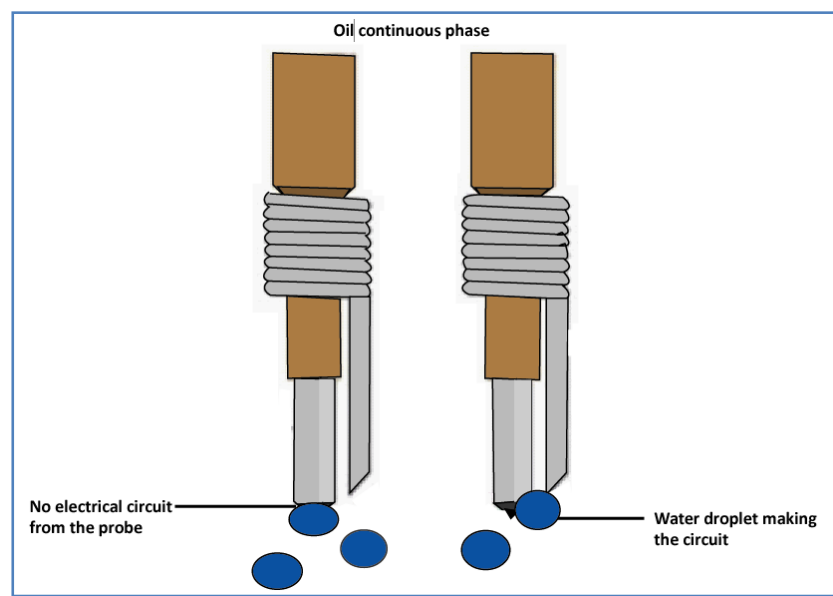

Figure3.8. Water holdup probe, oil-continuous phase, modified after [5]

\subsection{Pressure Measurement}

Pressure data from the production well can be obtained by various techniques. In modern production logging tool strings, there are mainly three kinds of pressure gauges. They are as follows:

a. Strain gauge

b. Sapphire Strain gauge

c. Quartz gauge

\subsection{Temperature Measurement}

There are temperature sensors in the production logging tool. This temperature sensor usually consists of a platinum wire. When temperature changes resistance of the wire also changes and it is observed in the sensor. This change of resistance further converted into temperature.

Temperature measurement by production log is so much important because it helps to analysis quality flow and casing leakage condition diagnosis. Beside it is also useful for checking the wellbore completion integrity.

\subsection{Production Log in Horizontal Well}

It is not so easy to run production log in the horizontal well as it is easy in the vertical well. There are several challenges to run production $\log$ in the horizontal well. Some modification is needed. In horizontal well, mainly three methods of log run prevail [19].

They are mentioned below.

a. If production tube is $2 \frac{3}{8}$ inch, coiled tubing of $1 \frac{1}{4}$ inch has to be run, fig. 3.9.

b. When production tube is $2 \frac{7}{8}$ inch, a tractor well is needed to deploy logging tool, fig. 3.10.

c. 2 inches coiled tubing can be used to insert the tool if production is up the casing.

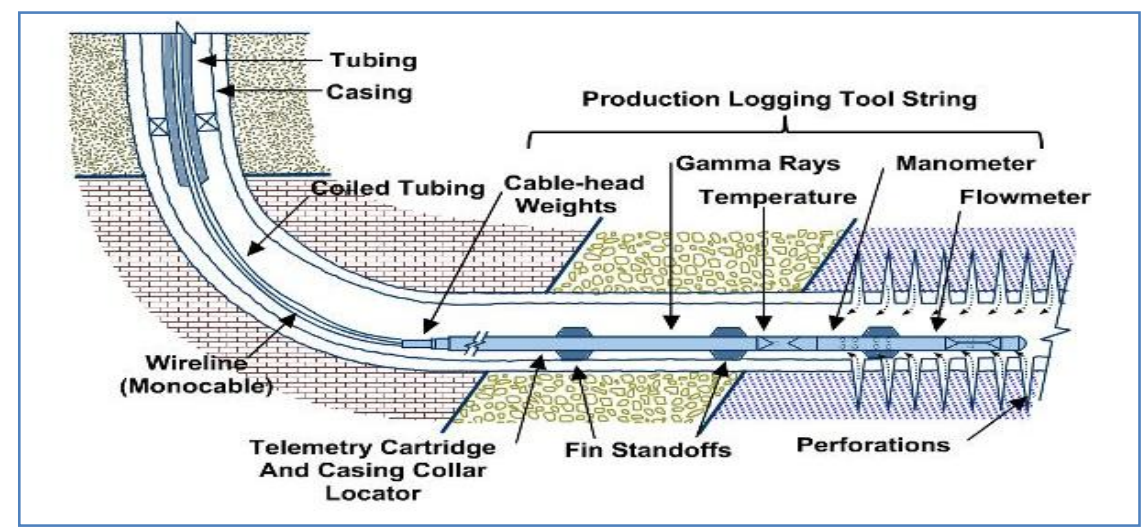

Figure3.9. Production logging tool run with $1 \frac{1 / 4}{4}$ inch coiled tubing through $23 / 8$ inch production tubing [19] 


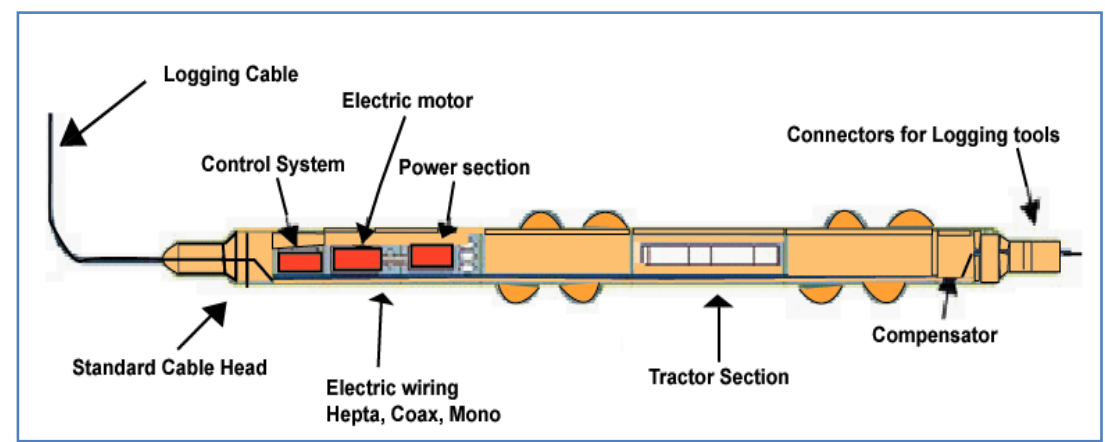

Figure3.10. Production logging tool being deployed with a down-hole Well Tractor Tool modified after [19]

In horizontal wells, segregation may occur. So, production logging tool has to be set in the center of the hole to measure properly segregation fluid. When there is stratified flow in horizontal well, special sensors are required to measure fluid flow and distribution across the wellbore properly.

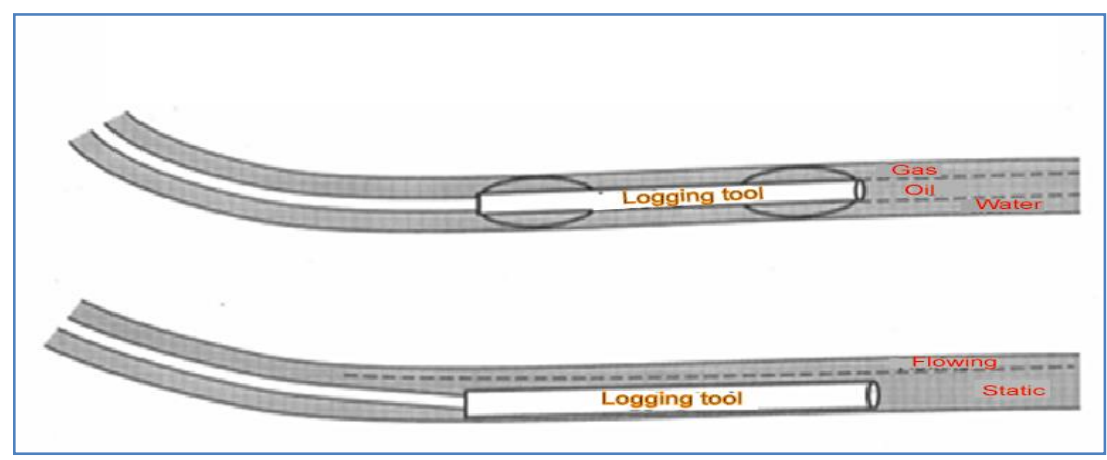

Figure3.11. logging tool position in segregated horizontal well, modified after [19]

\subsection{Production Logging Sensors for Horizontal Well}

A production logging tool for horizontal well has some difference than vertical well logging tool. A logging tool consisting sensors for horizontal well are shown in table 3.1 and fig.3.12 [19].

Table3.1. Production logging tool sensors for horizontal well

\begin{tabular}{|c|c|}
\hline Sensor type & Uses for \\
\hline Gamma ray & It is for depth correlation \\
\hline Collar Correlation Log & It is also for depth correlation \\
\hline Pressure & It measures the bottom hole flowing pressure \\
\hline Temperature & Measure fluid or gas inflow or channeling behind pipe \\
\hline Flow meter & Calculate the rate of flow from each interval of depth \\
\hline Fluid identification sensors & $\begin{array}{c}\text { This sensor identifies fluid type in two or three phase } \\
\text { flow region }\end{array}$ \\
\hline Fluid capacitance & $\begin{array}{c}\text { Difference between water and hydrocarbons are } \\
\text { measured }\end{array}$ \\
\hline Fluid density & Difference between water, oil and gas is measured \\
\hline
\end{tabular}

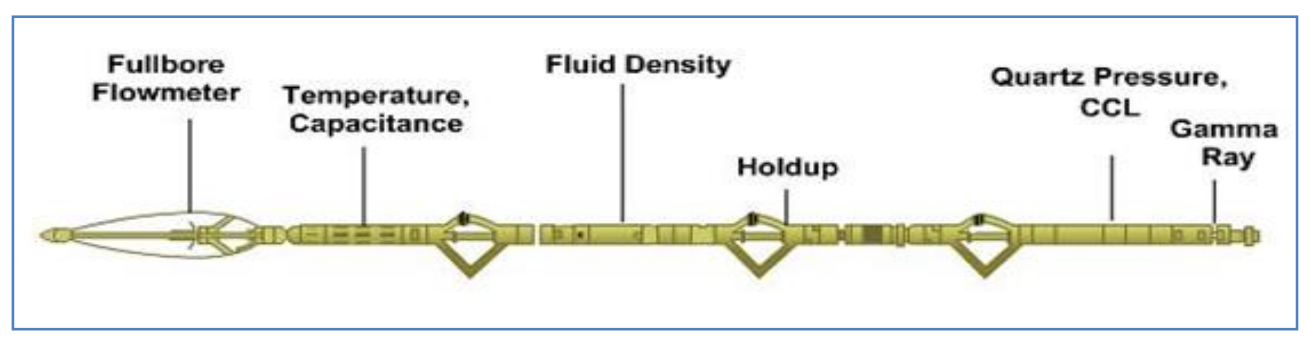

Figure3.12. Horizontal well production logging sensor package [19, 20]

\section{Conclusion}

Production logging is very much important to develop reservoir production modeling and processes. This is why it is important to understand the tools and techniques that are applied for the process. Production logging is also important for identifying production and completion anomalies and 
problems. A production log is usually run by the operator in a flowing wellbore. It helps to measure the zonal contribution of water or hydrocarbons to evaluate the flow performance model and stimulation effectiveness. Running production logs in horizontal wellbores presents unique challenges requiring modification not only to the tools but also in the delivery techniques. Unlike flow in a vertical well, in a horizontal well, wellbore production is different. Therefore, special sensors are required to properly measure the holdup across the lateral section.

\section{REFERENCES}

[1] Rider, M.H. 2002. The Geological Interpretation of Well Logs, 2nd edition, ISSN: 0-9541906-0-2

[2] Leyland, L. 2017. The Importance and Applications of Well Logging. Medium, 22 August 2017, https://medium.com/@ welllogging/the-importance-and-applications-of-well-logging-3fe97fd1fa0e (accessed 7 April 2019).

[3] Warren, J. 2018. Well (wireline) log interpretation of evaporites: An overview. Salty Matters, 31 March 2018, http://saltworkconsultants.businesscatalyst.com/blog/wireline-log interpretation-of-evaporites (accessed 7 April 2019).

[4] Davarpanah, A; Mirshekari, B; Behbahani, T.J; Hemmati, M. 2018. Integrated production logging tools approach for convenient experimental individual layer permeability measurements in a multi-layered fractured reservoir. Journal of Petroleum Exploration and Production Technology, https://doi.org/10.1007/s13202-017-0422-3

[5] Shad, S; Ardabili, R.J; Parhizgar, M. 2015. Production Logging techniques and Interpretation of resulted figure: A case study of a gas field Iran. The 4th conference of Petroleum Engineers and the upstream industry, May 28,2015, Tehran, Iran.

[6] Mukerji, P.A. 2013. Principles of production logging, Schlumberger. https://www.slb.com/media/ Files/resources/oilfield_review/defining_series/Defining-ProductionLogging.pdf?la=en\&hash=780441 1B6CB47 1039447A3C9348423C2B3031BA3

[7] Whittaker, A.C; Lenn, C.P; Hammond, P. 2006. Improving Multiphase Production Logging answers with the Mass-Fraction Spinner Response Model for gas-liquid flows, petrophysics, 47, No.2, pp 120-128.

[8] Bamforth, S.T; Besson, C.H; Stephenson, W.C; Brown, G.E. 1996. Revitalizing Production logging. Cambridge, England.

[9] Davarpanah, A; Mirshekari, B; Behbahani, T.J; Hemati, M. 2017. Application of production logging tools in estimating the permeability of fractured carbonated reservoirs: A comparative study. Journal of Petroleum and Gas Engineering, Vol. 8(5), pp. 36-41. DOI: 10.5897/JPGE2016.0245

[10] Petrowiki, 2018. Production logging (15 January 2018 modified), https://petrowiki.org/Production_loggin g\#cite_note-r2-2 (Accessed 7 April 2019).

[11] Petrowiki, 2018. Production logging (15 January 2018 modified), https://petrowiki.org/ Production_logging\# Pricing_for_production_logging (Accessed 7 April 2019).

[12] Gan, T; Balmain, B; Sigbatullin, A. 2016. Formation evaluation logoff results comparing new generation mining-style logging tools to conventional oil and gas logging tools for application in coalbed methane (CBM) field development. J Nat Gas Sci Eng 34(Supplement C):1237-1250. http s://doi.org/10.1016 /j.jngs e.2016 .07.070).

[13] Wilson, A. 2016. Production-logging tools facilitate well testing in challenging environments. J Pet Technol 68(02):79-80.

[14] Aghli, G; Soleimani, B; Moussavi-Harami, R; Mohammadian, R. 2016. Fractured zones detection using conventional petrophysical logs by differentiation method and its correlation with image logs. J Pet Sci Eng 142(Supplement C):152-162. http s://doi.org/10.1016 /j.petr ol.2016.02.002

[15] Al-Mulhim, A; Al-Thwaiqib, I; Bogari, A; Bawazir, M; Abdein, M. 2015. Integrated production logging approach for successful leak detection between two formations: a case study. Paper presented at the SPE annual technical conference and exhibition.

[16] Frooqnia, A; Torres-Verdín, C; Sepehrnoori, K. 2011. Numerical simulation and interpretation of production logging measurements using a new coupled wellbore-reservoir model. Paper presented at the SPWLA $52^{\text {nd }}$ annual logging symposium.

[17] Hoffman, B.T; Narr, W. 2012. Using production logs (PLT) to estimate the size of fracture networks. J Pet Sci Eng 98-99(Supplement C):11-18. http s://doi.org/10.1016 /j.petr ol.2012 .08.019

[18] Colin, W.H. 2013. Fundamentals of Production Logging, Schlumberger, Houston, Texas.

[19] Petroskills, 2018. What You Need to Know About Production Logging. 1 June 2018, https://www.petroskills.com/blog/entry/00_totm/june-18-sub-what-you-need-to-know-about-productionlogging\#.XKua6_0zbIV (Accessed 7 April 2019). 
[20] Heddleston and Duncan, 2009. Horizontal Well Production Logging Deployment and Measurement Techniques for US Land Shale Hydrocarbon Plays, SPE 120591 presented at 2009, SPE Production and Operations Symposium, Oklahoma City, Oklahoma, April 4 - 8, 2009.

[21] Liao, L. 2013. Interpretation of Array Production Logging Measurements in Horizontal Wells for Flow Profile, M.Sc thesis report, December, 2013, Texas A\&M University.

Citation: Mohammad Sumon Chowdhury, et.al, (2019). "Production Logging and its Implementation: A Technical Review”, International Journal of Petroleum and Petrochemical Engineering (IJPPE), 5(2), pp.42-51, DOI: http://dx.doi.org/10.20431/2454-7980.0502004

Copyright: (C) 2019 Authors. This is an open-access article distributed under the terms of the Creative Commons Attribution License, which permits unrestricted use, distribution, and reproduction in any medium, provided the original author and source are credited 